\title{
ATUAÇÃO DE LICENCIADOS EM EDUCAÇÃO FÍSICA NAS ACADEMIAS DE GINÁSTICA: UMA ANÁLISE A PARTIR DOS SABERES DOCENTES
}

\author{
Jairo Antônio Paixão \\ Universidade Federal de Ouro Preto, Ouro Preto, Minas Gerais, Brasil. \\ Glauber César Cruz Custódio \\ Universidade Federal de Ouro Preto, Ouro Preto, Minas Gerais, Brasil. \\ Yuri Windson Santos Barroso \\ Universidade Federal de Ouro Preto, Ouro Preto, Minas Gerais, Brasil.
}

\begin{abstract}
Resumo
O estudo analisou a atuação de licenciados em Educação Física em academias de ginástica, bem como a aquisição de saberes e competências necessárias a uma intervenção de qualidade, a partir de uma investigação de campo, descritiva e de cunho qualitativo com um grupo amostral de 26 licenciados atuantes como instrutores de academias de ginástica. Ainda que a formação inicial em licenciatura não os tenha preparado para atuarem diretamente no âmbito do bacharelado, verificou-se que, em sua atuação no referido âmbito profissional, os licenciados buscam realizar cursos de curta duração, acesso ao referencial teórico específico e o contato com bachareis como forma de complementar e aprofundar os conhecimentos relativos às atividades físicas desenvolvidas nas academias de ginástica.
\end{abstract}

Palavras chave: Atuação Profissional. Licenciado. Saberes. Academia de Ginástica.

\section{Introdução*}

As discussões que envolvem os contextos e cenários sociais em que decorrem a formação e atuação do profissional em Educação Física sempre mereceram destaque e preocupação no âmbito acadêmico brasileiro. No entanto, tais discussões ganharam maiores proporções, especialmente nas duas últimas décadas, em função de eventos como: vigência da atual LDB (Lei 9.394/96); a instituição da Lei 9.696/98, que dispõe sobre a regulamentação

\footnotetext{
* Artigo resultante de pesquisa desenvolvida no Laboratório de Estudos Pedagógicos em Educação Física (LEPEF), Centro Desportivo da Universidade Federal de Ouro Preto, MG e teve como órgão financiador o CNPQ no período de 01 de agosto de 2013 a 31 de julho de 2014.
}

Pensar a Prática, Goiânia, v. 17, n. 3, p. 701-717, jul./set. 2014 
da profissão em Educação Física; e a instituição das Diretrizes Curriculares Nacionais para os cursos de Educação Física por meio da Resolução CNE/CES n. 7/2004, que foi precedida por polêmicas até a sua aprovação em 2004 (BRASIL, 1996; BRASIL, 1998; BRASIL, 2004).

No epicentro desses debates e discussões, sempre esteve presente a dicotomia existente entre licenciatura e bacharelado, principalmente no que concerne às atribuições e competências específicas ligadas aos respectivos campos de intervenções.

Ainda que licenciatura e bacharelado em Educação Física se configurem como campos distintos de intervenção, percebe-se, na maioria dos cursos de formação, uma matriz curricular muito próxima, variando poucas disciplinas entre as duas habilitações, o que poderia levar a crer em mesmo perfil profissional, mesmas competências e um mesmo tipo de intervenção (SILVA, 2011).

Para a integralização da licenciatura, tem-se nas matrizes curriculares um número maior de disciplinas da chamada dimensão didática e pedagogia, e diminuição das disciplinas técnico-instrumentais; já o bacharelado, um aumento do número de disciplinas técnico-instrumentais, em relação à dimensão da didática e pedagogia. Essas informações mostram a dificuldade por parte das instituições de ensino em definir os objetivos e perfis profissionais do seu curso, que assim realmente diferenciem a licenciatura do bacharelado (SILVA, 2011).

Em decorrência da existência de uma especificidade entre uma habilitação e outra, a partir dos eventos mencionados e da própria historicidade que permeia a Educação Física enquanto área do saber e de intervenção, ocorre que os optantes pelo curso de licenciatura, por vezes, buscam uma formação voltada para o exercício profissional extraescolar.

Esses atores, ainda nessa fase, buscam articular diferentes estratégias para desenvolver competências necessárias à atuação profissional do bacharel, como a inserção em grupos de estudos e pesquisas nas áreas de fisiologia do exercício e treinamento esportivo, envolvimento em estágios extracurriculares efetivados em academias, além da participação em cursos e eventos científicos voltados ao fitness.

Estudos realizados por Rossi e Hunger (2008) e Krüger e Krug (2006) mostram que uma considerável parcela de licenciados em Educação Física chega a desconsiderar sua formação e busca firmar-se, profissionalmente, além dos limites da escola, espaço este que se destina exclusivamente ao bacharel.

O fato de uma parcela de licenciados encontrar-se atuando em academias de ginástica compõe um quadro preocupante, pois se coloca em discussão uma atuação profissional num campo para o qual estes sujeitos

Pensar a Prática, Goiânia, v. 17, n. 3, p. 701-717, jul./set. 2014 
não receberam formação específica.Vistas as coisas por essa perspectiva, ainda que o aprendizado docente não se limite à fase de formação acadêmico-profissional, na qual o futuro profissional encontra-se frente aos saberes que lhe alicerçarão no exercício da docência (TARDIF; RAYMOND, 2000), e que através das experiências (práticas) diretas com o fazer do próprio trabalho são aprendidos e produzidos saberes práticos ${ }^{1}$ essenciais ao exercício da prática profissional, chama a atenção o fato de os profissionais, com formação em licenciatura, vivenciarem saberes práticos em um campo que não corresponde àquele no qual se formaram ou se encontram em processo de formação. Essa situação suscita questionamentos sobre o tipo de atuação que estes sujeitos desempenham na academia, sua formação, a apreensão dos saberes e a aquisição, ou não, de competências específicas ao longo de suas trajetórias profissionais.

Ainda que prevaleça o esforço dos Conselhos Regionais de Educação Física em fiscalizar e coibir tal prática no âmbito de atuação profissional do bacharel na referida área de intervenção, lamentavelmente convive-se com tal problemática que se encontra vigente na área da Educação Física.

A partir do quadro apresentado, em que se tem o licenciado atuando no campo do bacharel em Educação Física, questiona-se não somente a forma de aquisição, como também o tipo de educação profissional deste e, por conseguinte, a qualidade do serviço prestado, numa área de intervenção que se relaciona à promoção e manutenção da saúde e qualidade de vida dos diferentes segmentos da população.

Desta forma, ao se considerar a atuação do licenciado no campo do bacharel, o presente estudo teve como objetivo analisar como se dá a aquisição de saberes e competências específicas e necessárias a uma intervenção de qualidade ao público que frequenta as academias de ginástica localizadas em três cidades do interior do Estado de Minas Gerais.

\section{Saberes, Competência e Atuação Profissional}

Durante muito tempo prevaleceu um consenso de que para ensinar bastava conhecer um conteúdo em questão. Tal concepção sustentou a ideia de que a experiência adquirida por um indivíduo por meio de experimentações práticas lhe garantiria sustentação necessária e suficiente no campo de intervenção (HUBERMAN, 2013). Tem-se acompanhado que, nas últimas décadas, a sociedade exige mais resultados das ações das instituições de

Os saberes práticos (ou experienciais), dentre as diferentes categorias de saberes que são apresentados por Tardif (2002), são aqueles que são adquiridos a partir da experiência direta com o trabalho, ou seja, através das ações desenvolvidas em seu lócus - a escola.

Pensar a Prática, Goiânia, v. 17, n. 3, p. 701-717, jul./set. 2014 
educação formal, o que se sintetiza na busca de qualidade (ZEICHNER, 2013).

Os estudos voltados para a área de formação evidenciam que a atuação profissional docente estrutura-se a partir de sucessivas interações do sujeito cognoscente com diferentes saberes, crenças, habilidades e competências específicas ao longo de sua trajetória (MONTEIRO, 2001; NÓVOA, 2003; NUNES, 2001; PERRENOUD, 2001, PIMENTA, 2007; SORIANO, 2003; STROOBANTS, 1997; TARDIF, 2002; TARDIF, GAUTHIER, 2001). Essa complexidade inerente à intervenção profissional não reside apenas na sofisticação erudita do conhecimento acadêmico, nem tão somente no aprimoramento tecnológico advindo do conhecimento científico, mas na articulação de diversos tipos de saberes e de recursos.

Ao realizar o trabalho de análise dos saberes que sustentam a prática docente, Monteiro (2001), Tardif (2002) e Pimenta (2007) destacam sua complexidade e afirmam que o processo de formação profissional docente alicerça-se sobre três saberes: acadêmicos, pedagógicos e experienciais. Os primeiros correspondem aos saberes científicos e/ou disciplinares e se relacionam às instituições formadoras.

A partir de disciplinas como didática, metodologia do ensino, prática de ensino e outras de cunho pedagógico, são difundidos os saberes pedagógicos que, por sua vez, se referem à relação que se estabelece entre professor-aluno no decorrer do processo instrucional, à capacidade de condução e elaboração de estratégias didático-metodológicas que visem à motivação e ao interesse dos alunos e, finalmente, ao emprego eficaz de técnicas ativas de ensinar.

Já os saberes experienciais constituem-se no exercício da prática cotidiana da profissão, fundados no trabalho e no conhecimento do meio. São saberes que surgem da experiência prática e são por ela validados a partir de uma íntima articulação com os demais saberes apreendidos pelo sujeito no período em que se encontra no curso de formação inicial. Incorporam-se à vivência individual e coletiva sob a forma de habilidades, de saber fazer. Em sua maioria são saberes que não advêm unicamente das instituições de formação. São saberes práticos e não da prática: eles não se aplicam à prática para melhor conhecê-la, eles se integram a ela e são partes constituintes dela enquanto prática docente (TARDIF, 2002).

No entanto, há que se ressaltar que o domínio desses saberes, que se fazem necessários à prática profissional docente, diferencia-se de profissional para profissional em decorrência de fatores ligados às especificidades do campo de atuação, do tipo de formação, bem como à própria subjetividade do sujeito profissional.

Pensar a Prática, Goiânia, v. 17, n. 3, p. 701-717, jul./set. 2014 
Nesse sentido, ter uma base de saberes na atuação profissional significa ter não somente conhecimento, mas também uma compreensão crítica de como esses saberes devem ser adequadamente relacionados com a prática (GRAÇA, 1999). Essa capacidade de empregar os saberes e habilidades diante de uma situação-problema no contexto específico do trabalho docente é denominada "competência" por Perrenoud (1999; 2000). Segundo o autor, a competência é a capacidade de agrupar um conjunto de aptidões cognitivas, como os saberes e as habilidades, para assim, solucionar de forma eficiente situações-problemas que podem se colocar no campo real de atuação profissional.

Tem-se tornado comum, nos diferentes âmbitos da sociedade, o emprego dos termos competência e padrão de qualidade como forma de associação e até mesmo como sinônimos, dada a íntima relação entre os mesmos, no seu entendimento. A busca por um padrão de qualidade no oferecimento de produtos e serviços tem sido uma constante nos mais diferentes setores que compõem a sociedade capitalista atual. Ainda que estivessem, nomeadamente, mais voltadas ao âmbito empresarial e trabalhista do que nos níveis educativos, nota-se, inicialmente a partir da década de 1990, na sociedade europeia, em países como por exemplo a Espanha, produções, discussões e propostas relacionadas ao desenvolvimento de competências na educação, efetivando-se pela atuação profissional docente (LE BOTERF, 2000; REY, 1996; LÉVY-LEVOYER, 2000; PERRENOUD, 1999; 2000; ZABALA, ARNAU, 2007).

Dentre as características fundantes do currículo por competências nos cursos de formação, encontra-se a ideia de competências específicas necessárias a uma atuação profissional de qualidade em uma determinada área de intervenção, vivências em experiências autênticas em contextos reais, com espaços à reflexão e debates entre os pares, tendo como base os saberes apreendidos no âmbito da formação educacional (TARDIF, 2002; GOÑI, 2012).

Considerando que o bacharel e o licenciado em Educação Física devem estar qualificados e preparados para atuarem em seu campo específico, e que devem ser detentores de saberes com vistas ao desenvolvimento das competências necessárias a uma intervenção de qualidade, Tardif (2000) argumenta que apenas os profissionais, em desacordo aos leigos e aos charlatães, possuem a formação e a capacidade para dominar estes saberes, podendo assim fazer o uso deles com exclusividade e legitimidade em sua prática de intervenção.

Recuperados, assim, brevemente, os aspectos inerentes à articulação dos saberes apreendidos na fase de formação inicial e o desenvolvimento de competências específicas no âmbito de intervenção, torna-se possível avan-

Pensar a Prática, Goiânia, v. 17, n. 3, p. 701-717, jul./set. 2014 
çar um pouco mais na análise da atuação profissional dos licenciados em Educação Física nas academias de ginástica - ambiente de intervenção profissional para o qual esses sujeitos não se encontram habilitados - subjacente aos saberes e competências especificas requeridas nesse campo de trabalho que, a princípio, volta-se exclusivamente ao bacharel em Educação Física.

\section{Método}

Considerando o fenômeno estudado, a trilha científica das Ciências Humanas e Sociais se mostrou a mais indicada para nortear a averiguação dos objetivos estabelecidos. Este estudo se caracteriza como uma pesquisa de natureza qualitativa (MINAYO, 2002). Como instrumento de coleta de dados, foi empregada a entrevista semiestruturada fundamentada na literatura especializada. $\mathrm{Na}$ análise dos dados, foi utilizada a técnica de análise de conteúdo (BARDIN, 2006).

Após análise qualitativa e interpretativa dos dados, estes foram categorizados e quantificados a partir da frequência de ocorrência nas falas dos sujeitos considerados nesse estudo. A amostra constituiu-se por 26 instrutores com formação exclusiva em licenciatura, atuantes em academias de ginástica localizadas em três cidades no interior do Estado de Minas Gerais. Como procedimento prévio à aplicação da entrevista, os sujeitos foram informados acerca dos aspectos relativos à pesquisa. Momento esse em que foi entregue um Termo de Consentimento Livre e Esclarecido (TCLE) que tratava do conteúdo da pesquisa realizada, e que foi lido e assinado pelos sujeitos participantes deste estudo.

Como critérios de inclusão dos sujeitos no grupo amostral da pesquisa foram considerados: instrutores com formação exclusiva em licenciatura em Educação Física atuantes em academias de ginástica. Foram considerados como critérios de exclusão: os instrutores que possuíam formação em bacharelado ou nenhuma formação na respectiva área de intervenção, a recusa da assinatura do TCLE e o não interesse em participar da investigação.

Em consonância com a resolução 466/12 da CONEP, a relação riscobenefício foi baixa, uma vez que houve apenas aplicação da entrevista, previamente agendada, com cada um dos sujeitos e os dados pessoais dos participantes foram omitidos. A pesquisa obteve aprovação junto ao Comitê de Ética em Pesquisa da Universidade Federal de Ouro Preto sob o registro número CAAE: 10282512.1.0000.5150, ofício CEP No. 006/2012, de 1 de Fevereiro de 2013.

\section{Resultados e Discussão}

Pensar a Prática, Goiânia, v. 17, n. 3, p. 701-717, jul./set. 2014 
A discussão desenvolveu-se através da triangulação entre os dados das entrevistas realizadas com os professores licenciados em Educação Física participantes, a bibliografia utilizada que vinha ao encontro da temática abordada,e também as posições assumidas pelos autores da investigação em relação ao tema.

Desta forma, foi possível uma compreensão e discussão aprofundada das categorias de análise que se encontram organizadas em duas partes: a primeira busca caracterizar o licenciado, sua formação e aspectos relacionados à sua atuação no âmbito de intervenção (academia de ginástica) destinado ao bacharel em Educação Física; a segunda parte aborda possíveis formas de aquisição e relação do licenciado com os saberes e competências específicas ao referido campo de intervenção profissional.

\section{Formação em licenciatura em Educação Física e atuação em academias de ginástica}

Ao se levantar aspectos relacionados à formação inicial e atuação em um campo de intervenção específico, como se configuram o do bacharelado e da licenciatura em Educação Física, foi notória, nos depoimentos dos entrevistados, a polêmica que envolve os contextos de formação e inserção do profissional de Educação Física no Brasil. O equívoco parece iniciar-se ainda no momento da escolha pelo curso. Uma parcela considerável dos entrevistados (87\%) alegou que, ao se inscreverem no processo seletivo (atual ENEM), o fizeram para o curso de Educação Física sem o conhecimento e/ou a preocupação da existência das duas habilitações (licenciatura e bacharelado) que especificam a área de atuação profissional. Esses mesmos sujeitos afirmaram que apesar do conhecimento sobre a especificidade existente na atuação do licenciado e do bacharel, ainda assim, a opção pelo curso de licenciatura se deu com a perspectiva de se trabalhar no âmbito extraescolar.

Durante a entrevista, os participantes apontaram os principais motivos da opção por atuar como instrutor de academia, bem como as formas de atuação nesse campo de intervenção profissional, como mostram as Tabelas 1 e 2 .

Pensar a Prática, Goiânia, v. 17, n. 3, p. 701-717, jul./set. 2014 


\begin{tabular}{|c|c|}
\hline \multirow{2}{*}{ Variáveis consideradas } & Licenciados \\
\hline & $\%$ \\
\hline Identificação com a academia como campo de intervenção profissional. & 36,52 \\
\hline Maior oportunidade de atuação nas academias & 23,80 \\
\hline Status proporcionado pela academia & 23,80 \\
\hline Não identificação com a licenciatura & 10,59 \\
\hline Problemas na escola como estrutura física, violência. & 5,29 \\
\hline TOTAL & 100 \\
\hline
\end{tabular}

TABELA 2 - Atuação profissional do licenciado

\begin{tabular}{lc}
\hline \multirow{2}{*}{ Variáveis consideradas } & Licenciados \\
\cline { 2 - 2 } & $\%$ \\
\hline & \\
Atuação exclusiva como instrutor de academia. & 65,4 \\
Atuação simultânea em academia e escola & 26,9 \\
Atuação em funções distintas a Educação Física & 7,7 \\
TOTAL & 100 \\
\hline
\end{tabular}

Os resultados demonstram maior identificação do sujeito pela academia de ginástica como campo de intervenção profissional. Como já mencionado, trata-se de um espaço de atuação destinado ao bacharel em Educação Física. Em contrapartida, esses mesmos sujeitos, em seus depoimentos, relataram uma série de fatores que desprivilegiam a escola como campo de intervenção profissional.

Dentre os fatores que vêm tornando a escola um ambiente sem maiores atrativos para professores em início de carreira, parecem prevalecer na maioria das escolas de rede pública aqueles relacionados com a falta de infraestrutura, de materiais didático-esportivos, apoio pedagógico e níveis alarmantes de indisciplina e violência. Esses fatores encontram-se em conformidade com aqueles apresentados em estudos na área (NAJLE; FLAMENGHI, 2007; BOTELHO; SOUZA, 2007; OLIVEIRA, 1999). 
Nesta perspectiva, como mostra a Tabela 2, os dados da presente pesquisa evidenciam a presença de licenciados em Educação Física nas academias de ginástica, os quais se encontravam dispostos da seguinte forma: $65,4 \%$ dedicavam-se exclusivamente a desempenhar a função de instrutor de academia; outros $26,9 \%$ se encontravam inseridos simultaneamente na academia e na escola; e os demais 7,7\% ocupavam profissionalmente funções distintas à área da Educação Física. Trata-se de fenômeno marcado pela contradição, onde se tem indivíduos que concluíram um curso de formação inicial para o campo de intervenção profissional da escola e, no entanto, buscam atuar em uma área para a qual não tiveram uma formação específica.

Vistas as coisas por essa perspectiva, os cursos de licenciatura e bacharelado em Educação Física são vertentes que não se contrapõem enquanto áreas do saber e, ainda que aspectos como promoção da saúde, qualidade de vida, área de intervenção social, cultural, histórica, econômica e política se configurem como uníssonas em sua estruturação, tratam-se de formações que se destinam a preparar o sujeito para atuar em campos distintos e em diferentes perspectivas nas demandas que se fazem presentes na sociedade atual.

Nesses termos, não é demais repetir que a formação de licenciatura em Educação Física não prepara o profissional para atuar no âmbito do bacharelado, por exemplo, ele não está apto a conduzir as diferentes ginásticas de grupo e musculação oferecidas pelas academias. Essa situação se mostrou muito mais complexa pelo entendimento dos próprios licenciados, que não percebem as especificidades existentes entre as duas habilitações.

Nessa perspectiva, a grande maioria $(84,6 \%)$ afirmou que os saberes adquiridos no curso de licenciatura os preparavam plenamente para o exercício da função de instrutores de academia. Tal alegação se fundamenta no fato de esses sujeitos terem cursado disciplinas da área biológica como, por exemplo, cinesiologia, treinamento esportivo e fisiologia do exercício.

O entendimento desse achado vai exigir uma revista nos estudos de Silva (2011) que afirma que, apesar das especificidades existentes entre licenciatura e bacharelado, e que, por sua vez, as duas modalidades formam profissionais para campos de intervenções distintos, a maioria das matrizes curriculares dos cursos de formação em Educação Física apresenta-se equivocadamente, ou ainda por conveniência da própria Instituição de Ensino Superior com expressiva similitude.

\section{Aquisição de saberes e competências específicas do bacharel em Educa- ção Física pelo licenciado}

Pensar a Prática, Goiânia, v. 17, n. 3, p. 701-717, jul./set. 2014 
Como mencionado, ainda que o curso de licenciatura tenha a função precípua de formar e habilitar o sujeito para intervir na Educação Básica, é recorrente na Educação Física encontrar licenciados em um campo de intervenção - bacharelado - para o qual não obtiveram formação inicial. Nesse sentido, fez-se necessário identificar junto aos entrevistados os caminhos adotados por eles na aquisição de conhecimentos específicos sobre as atividades em que atuam como instrutores de academia, como se pode verificar na Tabela 3.

\section{TABELA 3- Formas de aquisição dos conhecimentos específicos sobre as atividades de academia}

\begin{tabular}{lc}
\hline Variáveis consideradas & \multicolumn{1}{c}{ Licenciados } \\
\cline { 2 - 2 } & $\%$ \\
Contatos com profissionais formados do bacharelado & 49,29 \\
Referencial teórico (livros, artigos) & 29,58 \\
Cursos e eventos na área do bacharelado & 21,13 \\
TOTAL & 100 \\
\hline
\end{tabular}

Dentre os caminhos apontados pelos licenciados em Educação Física para a aquisição de conhecimentos específicos sobre as atividades de academia, as maiores frequências concentram-se nas categorias "contatos com profissionais formados no bacharelado", "referencial teórico como livros e artigos" e "através de cursos e eventos na área do bacharelado".

Ainda que se evidencie um esforço por parte dos profissionais licenciados no sentido de buscarem caminhos alternativos para a aquisição de conhecimentos a fim de atuarem no âmbito do bacharelado, a disposição em que se encontram esses profissionais dista muito de ser a mais adequada no que se refere à sua prática, pelo fato da inexistência de uma formação inicial específica para determinada área. Isso, por sua vez, poderá comprometer processos subsequentes à formação acadêmica que, indubitavelmente, contribuiriam no desenvolvimento de competências específicas, como apresentado em estudos desenvolvidos por Tardif e Raymond (2000). Esses autores analisaram o processo de edificação dos saberes profissionais docentes a partir de uma articulação de diferentes saberes, os quais se encontram atrelados a uma formação inicial e associados às experiências práticas no campo de trabalho.

Outro estudo apresentado por Zabala e Arnau (2007) reforça essa ideia ao postular que os processos formativos dos profissionais costumam dividir-se, classicamente, em três etapas sucessivas. A primeira é denomina-

Pensar a Prática, Goiânia, v. 17, n. 3, p. 701-717, jul./set. 2014 
da 'Formação Inicial' e costuma desenvolver-se em instituições educativas como um requisito inicial para uma trajetória profissional. A segunda dessas fases costuma ser chamada de 'Período de Indução' e faz referência à etapa que cobre os primeiros anos da vida do trabalho, etapa em que o profissional, no início de sua trajetória, vai habituando-se ao trabalho que vai realizar. Por último, está a fase que se denomina 'Formação Permanente' e que corresponde aos profissionais na ativa que já têm uma prática consolidada.

A formação inicial pode, sem dúvida, desenvolver competências básicas e gerais que serão a base do desenvolvimento de outras mais específicas no exercício da profissão. Os licenciados em Educação Física atuantes no âmbito do bacharelado (academias de ginástica) não dispõem de saberes adquiridos na fase de formação inicial (TARDIF, 2002) que lhes possam assegurar uma reflexão da prática. Estes saberes, como já indicado no ponto anterior, parecem o melhor caminho para o desenvolvimento das competências profissionais.

Ao discutir, no presente estudo, o contexto de atuação profissional em que se encontram os licenciados, bem como os aspectos relacionados à aquisição de conhecimentos inerentes à área do bacharelado, buscou-se conhecer a intenção futura dos referidos profissionais em cursar o bacharelado em Educação Física. De acordo com os depoimentos obtidos, quase a totalidade dos licenciados atuantes em academias de ginástica $(92,3 \%)$ admite tal necessidade e, com isso, afirmou tal intenção.

Diante do quadro apresentado, trata-se de uma situação que, de certa forma, confirma a complexidade no âmbito de formação profissional docente e, de forma mais pontual, se refere a uma intervenção de qualidade oferecida em áreas voltadas ao bacharel. Áreas que se relacionam diretamente com a promoção, reestabelecimento e manutenção da saúde e qualidade de vida das pessoas que buscam tal prestação de serviço na sociedade atual.

\section{Conclusão}

A preocupação em investigar a atuação do licenciado em Educação Física em academias de ginástica permitiu colocar no epicentro os contextos de uso dos saberes e competências profissionais no centro do debate proposto neste estudo. A presença do licenciado como protagonista de um campo de intervenção voltado ao bacharel em Educação Física denota um fato singular nessa área de conhecimento e ocupação profissional que, apesar de se configurar como alvo de inúmeros debates e discussões que ganharam maior abrangência nas duas últimas décadas, parece estar longe de um desfecho final.

Pensar a Prática, Goiânia, v. 17, n. 3, p. 701-717, jul./set. 2014 
Nesta ambiência, situar os saberes e competências necessárias ao exercício profissional do bacharel e as formas de sua articulação pelo licenciado traduz-se na preocupação pela qualidade dos serviços prestados em uma área que busca a promoção da saúde e qualidade de vida das pessoas.

Dentre os fatores que concorrem para a manutenção desta situação, é possível destacar aqueles que se relacionam à forma como se dá a escolha pelo curso de Educação Física. Parece prevalecer, por parte do candidato, uma concepção que restringe a área de atuação em Educação Física (com a ambiência do bacharelado) à atuação em academias e atividades de personal trainner. Na falas dos entrevistados, a área do bacharelado, se comparada com a da licenciatura, tem o potencial de lhes proporcionar status social, visibilidade, além de maiores oportunidades de se firmarem no mercado de trabalho.

Por sua vez, a escola, para esses sujeitos com habilitação para atuar na Educação Básica, se mostra como um campo de batalhas no qual eles se veem diante de problemas constantes como indisciplina, precariedade de recursos materiais e espaços para as aulas, bem como a remuneração salarial pelos serviços ali prestados.

Outro fator que merece ser mencionado se relaciona à forma como as matrizes curriculares dos cursos são organizadas, o que, por sua vez, leva a um processo de formação em que a construção de uma identidade pela área do bacharelado ou licenciatura, por parte do acadêmico, se torna comprometida. Esse fato propicia uma falsa ideia de abrangência ilimitada de atuação profissional para áreas em que não se teve uma formação inicial específica.

A aquisição e articulação de saberes e competências específicas para a atuação no campo do bacharelado, com ênfase às atividades de academias, ocorrem de diferentes formas como o contato direto com profissionais formados e atuantes, referenciais teóricos, cursos de curta duração e eventos da área. Somado a isso, foram evidenciados nos depoimentos dos entrevistados o desejo e a necessidade de se ingressar no curso de bacharelado em Educação Física.

Essa situação confirma o fato, ora defendido neste estudo, de que a formação inicial em licenciatura não proporciona os saberes específicos e necessários para uma atuação nas áreas de intervenção do bacharelado. Vale ressaltar que, ainda que estejamos nos referindo ao campo da Educação Física, licenciatura e bacharelado configuram-se como cursos distintos com áreas de atuações específicas.

Ainda que se perceba por parte dos licenciados um esforço na busca dos saberes visando o desenvolvimento de competências específicas a uma área de atuação diversa daquela para a qual tenham se formado, torna-se

Pensar a Prática, Goiânia, v. 17, n. 3, p. 701-717, jul./set. 2014 
obscuro predizer como o processo de aquisição desses saberes ocorre, em que condições e com que tipo de profissional. Isso porque os primeiros anos de atuação profissional são decisivos para o desenvolvimento das competências profissionais. É muito comum que os recém formados tentem adequar a sua maneira de agir ao que é considerado "normal" no meio em que se profissionalizam, absorvendo a cultura laboral do local de trabalho e contatos com demais profissionais na mesma área de intervenção ou áreas correlatas.

Nessas condições, corre-se o risco de se ter uma atuação profissional que dista de ser uma atuação reflexiva e consistente, convertendo-se em um ativismo acrítico. Assim, mesmo com o passar dos anos, a experiência acumulada poderá apenas servir para autojustificar as próprias ações destes profissionais e desenvolver neles uma atitude defensiva frente à sua atuação profissional em uma área para a qual não tenham se formado.

\title{
PERFORMANCE OF LICENSEES IN PHYSICAL EDUCATION AT GYMS: AN ANALYSIS BASED ON THE TEACHER KNOWLEDGE
}

\begin{abstract}
The study examined the performance of licensees in Physical Education at gyms, and also the acquisition of knowledge and specific and necessary skills to a quality intervention. It was conducted an analysis from a field investigation, descriptive and of qualitative approach, with a sample group of 26 licensed physical education teachers acting as instructors in gyms. Although the initial licensure formation has not prepared them to act directly in the scope of the bachelor, it was found that, in their work in the professional context, that licensees seek to do short courses, have access to specific theoretical referential and contact with Bachelors as a complement and a way of deepening the knowledge related to the physical activities in the gyms.
\end{abstract}

Keywords: Performance. Licensees. Knowledge. Gym.

\section{ACTUACIÓN DE LICENCIADOS EN EDUCACIÓN FÍSICA EN GIMNASI- OS: UNA ANÁLISIS A PARTIR DEL CONOCIMIENTOS DOCENTES}

\section{Resumen}

El estudio analisó la actuación de licenciados en Educación Física en Gimnasios, como también la adquisición de conocimientos y competencias específicas necesarias para obtener una intervención de calidad. Se realizó un análisis que comenzó con una investigación de campo descriptiva y de carácter cualitativa con un grupo de muestra de veintiséis licenciados que actuan como instructores de gimnasios. Mismo que la formación inicial en licenciatura no los haya preparado

Pensar a Prática, Goiânia, v. 17, n. 3, p. 701-717, jul./set. 2014 
para actuar directamente en el ámbito de intervención de título de grado,se verificó que en su trabajo en este referido ámbito profesional, los licenciados realizan cursos de corta duración, acceso a lo teórico específico y el contacto con los graduados universitarios como forma de complementar y profundizar los conocimientos relativos a las actividades físicas desarrolladas en los gimnasios.

Palabras-claves: Actuación Profisional. Licenciado. Conocimientos. Gimnasios.

\section{Referências}

BARDIN, Laurence. Análise de conteúdo. Trad. Luís Antero Reto e Augusto Pinheiro. 4ª ed. Lisboa: Edições 70, 2006.

BOTELHO, R. G.; SOUZA, J. M. C. Bullying e educação física na escola: características, casos, consequências e estratégias de intervenção. Revista de Educação Física v.1, n. 139, p. 58-70, 2007.

BRASIL. Lei 9.394 de 20 de novembro de 1996. Estabelece as diretrizes e bases da educação nacional. 1996. Disponível em: http://www.planalto.gov.br/ccivil_03/Leis/L9394.htm. Acesso em: 10 jun. 2013.

. Lei 9.696 de 01 de setembro de 1998. Dispõe sobre a regulamentação da Profissão de Educação Física e cria os respectivos Conselho Federal e Conselhos Regionais de Educação Física. Brasília: Ministério da Educação, 1998. Disponível em: http://www.planalto.gov.br/ccivil_03/Leis/L9696.htm. Acesso em: 10 jun. 2013.

Ministério da Educação/Conselho Nacional de Educação/Câmara de Educação Superior. Resolução n ${ }^{\circ}$ 7, de 31 de março de 2004. Diretrizes Curriculares Nacionais para os cursos de graduação em Educação Física. Brasília: MEC, 2004b. Disponível em: http://portal.mec.gov.br/cne/arquivos/pdf/ces0704edfisica.pdf. Acesso em: 10 jun. 2013.

GOÑI, J. M. Desarrollo de competencias. Barcelona: Funiber, 2012.

GRAÇA, A. Conhecimento do professor de educação física. In: Bento, J. O.; R. Garcia, R.; Graça, A. (orgs). Contextos da pedagogia do desporto. Lisboa: Livros Horizontes, p. 166-251, 1999.

HUBERMAN, M. Ciclo de vida profissional dos professores. In: NÓ- 
VOA, A. (org.) Vida de professores. $2^{\mathrm{a}}$ ed. Porto/Portugal: Porto Editora, p.31-61, 2013.

KRÜGER, L. G.; KRUG, H. N. Desvelando a atuação profissional em educação física através da percepção da trajetória acadêmica. Revista Mackenzie de Educação Física e Esporte. São Paulo, v. 5, n.1, p.77-92, 2006.

LE BOTERF, G. Ingeniería de las competências. Barcelona: Gestión, 2000.

LÉVY-LEVOYER, C. Gestión de las competências, como analizarlas, como evaluarlas, como desarrollarlas. Barcelona: Gestión, 2000.

MONTEIRO, A. M. F. C. Professores: entre saberes e práticas. Educação \& Sociedade. 22 (74), 2001. Disponível em: $\langle$ http://www.scielo.br/scielo $>$. Acesso em: 10 jun. 2013.

MINAYO, Maria C. S. (org.) Pesquisa Social: teoria, método e criatividade. $27^{\mathrm{a}}$ ed. Petrópolis: Vozes, 2002.

NAJLE, C. P. M; FLAMENGHI, G. A. Relação professores-alunos com dificuldades de aprendizagem e comportamento: história de mudanças. Cadernos de Pós-Graduação em Distúrbios do Desenvolvimento, São Paulo, v.7, n.1, p.97-111, 2007.

NÓVOA, A. Profissão professor. $2^{\text {a }}$ ed. Porto: Porto Editora, 2003.

NUNES, C. M. Saberes docentes e formação de professores: um breve panorama da pesquisa brasileira. Educação \& Sociedade. 22 (74), 2001. Disponível em: 〈http://www.scielo.br/scielo >. Acesso em 10 jun. 2013.

OLIVEIRA, M. A. T. Existe espaço para o ensino de educação física na escola básica? Pensar a Prática, v. 2, p.119-135, 1999.

PERRENOUD, P. Construir as competências desde a escola. Editora Artmed: Porto Alegre, 1999.

Dez novas competências para ensinar. Porto Alegre: Artmed, 2000. 
. Ensinar: agir na urgência, decidir na incerteza. Porto Alegre: Artmed, 2001.

PIMENTA, S. G. Saberes pedagógicos e atividade docente. $5^{\text {a }}$ ed. São Paulo: Cortez, 2007.

REY, B. Les compétences transversales em question. Paris: ESF editeur, 1996.

ROSSI, Fernanda; HUNGER, Dagmar Aparecida Cynthia França. Formação acadêmica em Educação Física e intervenção profissional em Academias de Ginástica. Revista Motriz, Rio Claro, v.14, n. 4, p. 440-451, out./dez. 2008.

SILVA, O. O. N. Licenciatura e Bacharelado em Educação Física: diferenças e semelhanças. Revista Espaço Acadêmico, Maringá, v.1, n. 124, p. 7684, set. 2011.

SORIANO, J. B. A constituição da intervenção profissional em educação física: interações entre o conhecimento formalizado e noção de competência. Tese de doutorado não-publicada, Programa de Pós-Graduação em Educação Física. Universidade Estadual de campinas, São Paulo, Brasil, 2003.

STROOBANTS, M. A visibilidade das competências. In: ROPÉ, F.; TANGUY, L. (orgs). Saberes e competências: o uso de tais noções na escola e na empresa. Campinas: Papirus, p. 135-166, 1997.

TARDIF, M.; RAYMOND, D. Saberes, tempo e aprendizagem do trabalho no magistério. Revista Educação e Sociedade, Campinas, v. 21, n. 73, p. 209-244, dez. 2000.

. Saberes profissionais dos professores e conhecimento universitário. Revista Brasileira de Educação, v.1, n. 13, p. 05-24, jan./ fev./mar./ abr. 2000 .

.; GAUTHIER, C. O professor como ator racional: que racionalidade, que saber, que julgamento? In: PERRENOUD, P.; PAQUAY, L.; ALTET, M.; CHARLIER, E. (orgs.), Formando professores profissionais. Quais estratégias? Quais competências? $2^{\mathrm{a}}$ ed. Porto Alegre: Artmed, p. 177201, 2001.

Pensar a Prática, Goiânia, v. 17, n. 3, p. 701-717, jul./set. 2014 
. Saberes docentes e formação profissional. Petrópolis: Vozes, 2002.

ZABALA, A.; ARNAU, L. 11 ideias clave: como aprender y enseñar competências. Barcelona: Graó, 2007.

ZEICHNER, K. M. Políticas de formação de professores nos Estados Unidos: como e por que elas afetam vários países do mundo. Belo Horizonte: Autêntica, 2013.

Recebido em: 27/04/2014

Revisado em: 23/06/2014

Aprovado em: 27/06/2014

Endereço para correspondência:

jairopaixao2004@yahoo.com.br

Jairo Antônio Paixão

Universidade Federal de Ouro Preto, Reitoria.

Morro do Cruzeiro s/n

Centro

35400-000 - Ouro Preto, MG - Brasil 